\title{
HUMAN SPINAL CORD IMPEDANCE: ITS APPLICATION IN NEUROSURGICAL STEREOTAXIC CORDOTOMY
}

\author{
James Arthur Taren, M.D., and Ross Davis, M.D. \\ University of Michigan Medical Center \\ Ann Arbor, Mich.
}

\section{INTRODUCTION}

Surgical access to the central nervous system has, for the most part, been obtained through operations that provide wide exposure and direct visualization of the target area. However, the application of radiologic and electrophysiologic techniques to neurosurgery permit reduction of the magnitude of the operative exposure without sacrifice of any of the surgical goals.

Operations to relieve pain are based on our knowledge of "pain pathways," which is admittedly imperfect. The relief of suffering remains one of the first responsibilities of the physician. While acute pain may act as a warning signal, chronic pain serves no such useful purpose and may lead to total incapacitation of the patient. This is true whether the pain is caused by malignancy or by an otherwise harmless condition.

Surgical destruction by cordotomy of the pain pathway in the spinal cord (the lateral spinothalamic tract) has been used for more than $\mathbf{5 0}$ years to treat intractable pain states. ${ }^{1,2}$ The recent conversion of a cordotomy from an open visual procedure to a closed stereotaxic procedure has extended the benefits of cordotomy to many more patients, ${ }^{3}$ but to reduce the hazard of this technique it is necessary that the four steps of stereotaxic surgery be followed: 1) definition of the radiologic coordinates of the target; 2) the use of a precision apparatus to approach the target; 3 ) physiologic confirmation of the target; and 4) precise destruction of the target. To eliminate any one of these steps is to increase the hazard to the patient.

\section{THE TARGET}

Destruction of the lateral spinothalamic tract of the second cervical cord segment usually results in a contralateral loss of superficial pain, temperature, deep pain, and visceral pain below a level of $\mathrm{C} 3$ or C4. The hazards of cordotomy at this level are chiefly due to anatomic variation and the proximity of other important pathways as well as the variation in the position of the tracts with the size and position of the motor decussation (FIGUREs $1 \& 2$ ).

A descending respiratory pathway, the ventrolateral reticulospinal tract, is probably intermingled with and deep to the fibers of the anterior part of the lateral spinothalamic tract. Unilateral destruction of this pathway results in little functional respiratory loss unless contralateral respiratory function is poor. Bilateral lesions involving the anterior portion of the lateral spinothalamic tract have been extremely dangerous in that patients may lose their ability to breathe while sleeping. For bilateral pain relief, a stereotaxic cordotomy may be performed at $\mathrm{C} 2$ and 7-10 days later at a lower cervical level by the anterior technique of Lin and co-workers. ${ }^{6} A$ variation in the level of the motor decussation that usually extends from the obex to the $\mathrm{C} 1$ level and the presence of aberrant corticospinal tracts may pose additional hazards.

\section{RADIOLOGIC COORDINATES}

The technique of Mullen, ${ }^{4}$ as modified by Rosomoff, ${ }^{5}$ is used for high cervical stereotaxic cordotomy, and that of Lin and associates ${ }^{6}$ by anterior cervical cor- 


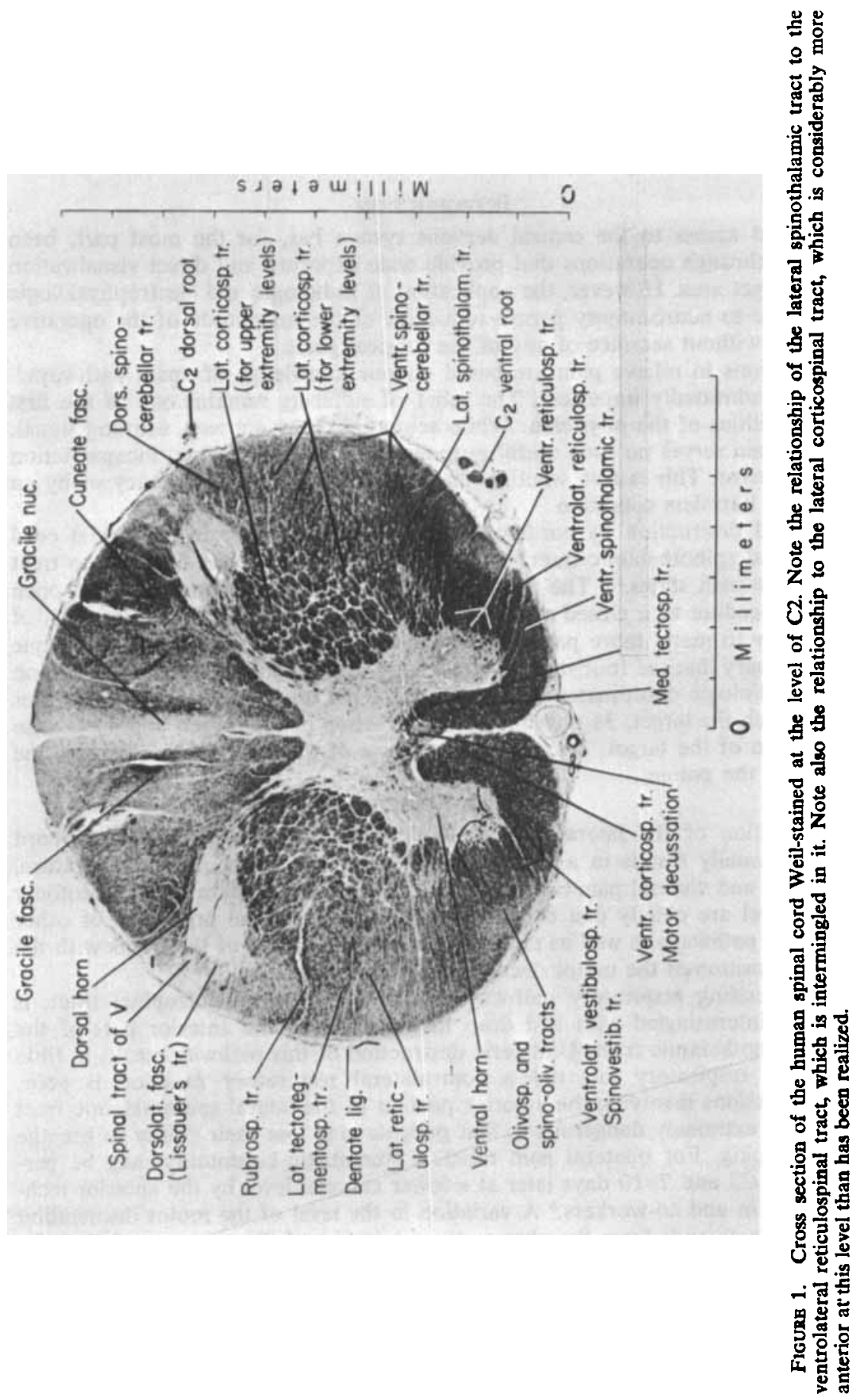


Taren \& Davis: Human Spinal Cord Impedance

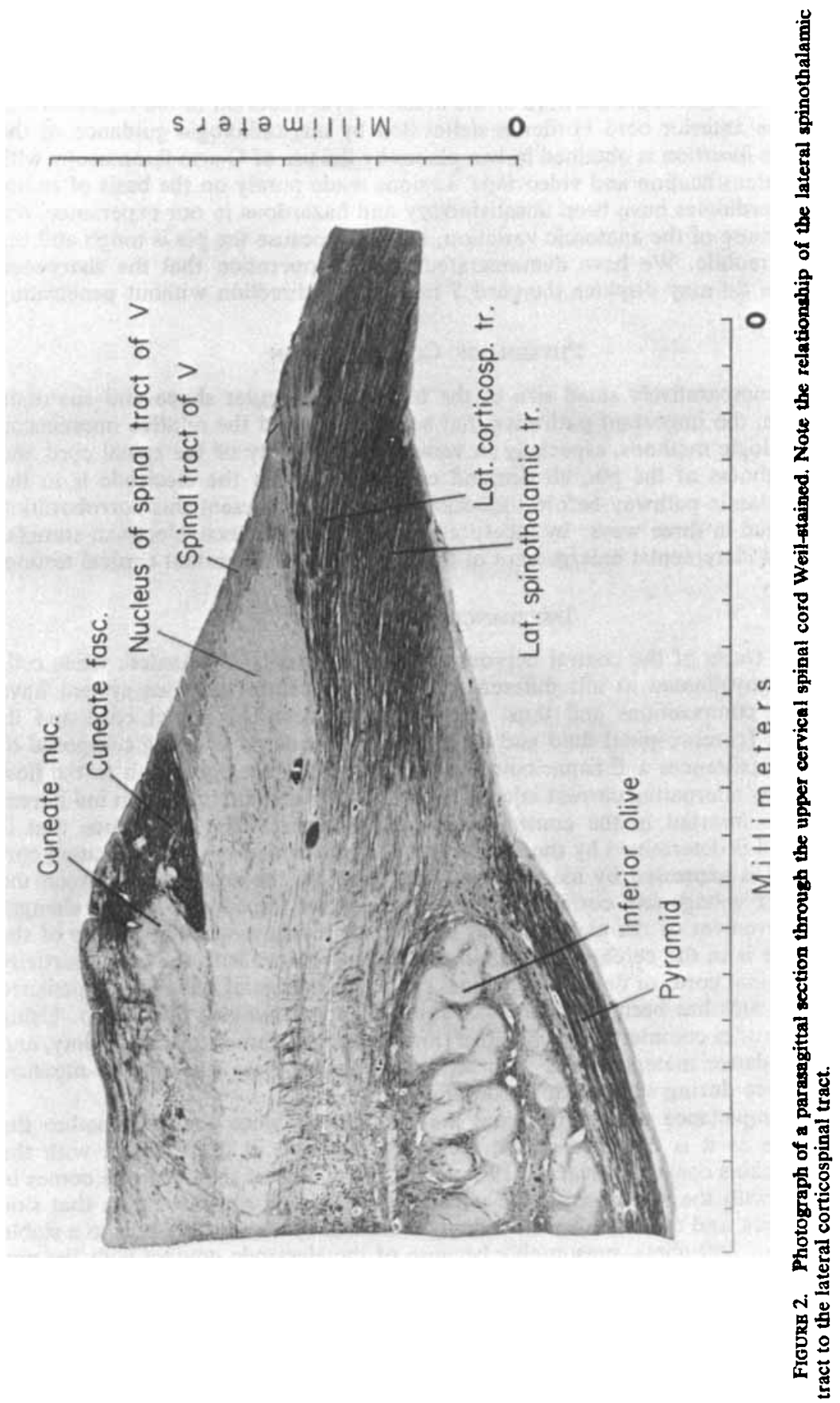


dotomy. Analgesic agents can be used to supplement local anesthesia when necessary; the goal is to have a drowsy patient who can, however, be awakened and who can cooperate during the procedure. A thin-walled 18-gauge spinal needle is inserted to penetrate the dura of the anterolateral quadrant in the region of $\mathrm{C} 2$. After the anterior cord border is delineated by air, radiologic guidance of the electrode insertion is obtained in two planes by the use of C-arm fluoroscopy with image intensification and video tape. Lesions made purely on the basis of radiologic coordinates have been unsatisfactory and hazardous in our experience, not only because of the anatomic variation, but also because the pia is tough and the cord is mobile. We have demonstrated at open operation that the sharpened electrode tip may displace the cord $5 \mathrm{~mm}$ in any direction without penetrating the pia.

\section{Physiologic CORRoboration}

The comparatively small size of the target, its irregular shape and anatomic variation, the important pathways that surround it, and the relative imprecision of radiologic methods, especially in view of the mobility of the spinal cord and the toughness of the pia, all demand confirmation that the electrode is in the spinothalamic pathway before the lesion is made. At present this corroboration is obtained in three ways: by measurement of the impedance, electrical stimulation, and incremental enlargement of the lesion with concomitant clinical testing.

\section{IMPEDANCE MEASUREMENT}

Some tracts of the central nervous system are heavily myelinated, while cells are not myelinated at all; different parts of the central nervous system have different compositions and thus, physical properties. The spinal cord and its environs (cerebrospinal fluid and air) may be considered as being composed of various resistances and capacitances which offer different opposition to the flow of the tiny alternating current injected between the electrode tip and an indifferent electrode inserted in the contralateral deltoid muscle. The impedance that is measured is determined by the alternating voltage divided by the alternating current and is expressed by magnitude (ohms) and by the angle $(\theta)$ between the phases of voltage and current. The measurement of impedance and its changes with movement of the electrode has enabled us to know whether the tip of the electrode is in the cerebrospinal fluid, merely in contact with the cord, partially in the spinal cord, or deep in the spinal canal. The range of values of impedance at these sites has been established in animals and in humans (TABLE 1). Using the electrodes commercially available* for the human stereotaxic cordotomy, and an impedance meter $\dagger$ linked with an X-Y recorder, $\ddagger$ we are able to measure impedance during stereotaxic cordotomy.

The impedance of cerebrospinal fluid is known, since the fluid bathes the electrode as it is threaded down; the value recorded at first contact with the fluid remains constant (average $190 \mathrm{ohms}$ ). As the tip of the electrode comes in contact with the spinal cord, the patient complains of sharp pain on that side of the neck and the impedance suddenly increases by about 100 ohms to a stable reading of $290 \mathrm{ohms}$, presumably because of the electrode contact with the pia. Advance of the electrode causes gradual increase of the impedance by an average

\footnotetext{
- Codman \& Shurtleft, Inc., 120 Auckland Street, Boston, Mass., trochar pointed Teflon insulated electrode wires, with a 3-mm-long tip.

† Hewlett-Packard Co., Pasadena, Calif., model 4800.

\$ Hewlett-Packard Co., Pasadena, Calif., Mosley model 7001 AR.
} 
Taren \& Davis: Human Spinal Cord Impedance

TABLE 1

Impedance Measurements Showing Steplike Relationships of Impedance to ELECTRODE ADVANCEMENT*

\begin{tabular}{|c|c|c|c|c|c|c|c|c|c|}
\hline & Cose & & & Contac & Cord & $\ln 0$ & & After L & sion \\
\hline & $\begin{array}{l}\text { CAT } \\
\text { open cord }\end{array}$ & $\begin{array}{c}Z \\
180\end{array}$ & $\begin{array}{c}\theta \\
57\end{array}$ & $\begin{array}{c}Z \\
280\end{array}$ & $\begin{array}{c}\theta \\
29\end{array}$ & $\begin{array}{c}Z \\
468\end{array}$ & $\begin{array}{c}\theta \\
29\end{array}$ & $\begin{array}{c}Z \\
350\end{array}$ & $\begin{array}{l}\theta \\
3\end{array}$ \\
\hline & $\begin{array}{l}\text { P.J. } \\
\text { open cord }\end{array}$ & 168 & 30 & 300 & 90 & 410 & 90 & - & - \\
\hline & $\begin{array}{l}\text { H. H. } \\
\text { open cord }\end{array}$ & 325 & 64 & 440 & 59 & - & - & - & - \\
\hline & $\begin{array}{l}\text { P. B. } \\
\text { s.c. }\end{array}$ & 148 & 48 & 300 & 38 & 458 & 55 & - & - \\
\hline & $\begin{array}{l}\text { J.L.H. } \\
\text { S.C. }\end{array}$ & 175 & 48 & - & - & 422 & 30 & 1000 & 43 \\
\hline & $\begin{array}{l}\text { G.F. } \\
\text { s.C. }\end{array}$ & 191 & 11 & 300 & 7 & 680 & 6 & 900 & 8 \\
\hline & $\begin{array}{l}\text { B. V. } \\
\text { s.c. }\end{array}$ & 151 & 42 & 239 & 40 & 520 & 20 & - & - \\
\hline & $\begin{array}{l}\text { J.J. } \\
\text { s.c. }\end{array}$ & 200 & 28 & 310 & 42 & 350 & 43 & 375 & 25 \\
\hline & E.C. & 288 & 44 & 366 & 60 & 463 & 65 & 600 & 55 \\
\hline
\end{tabular}

S.C. refers to stereotaxic cordotomy.

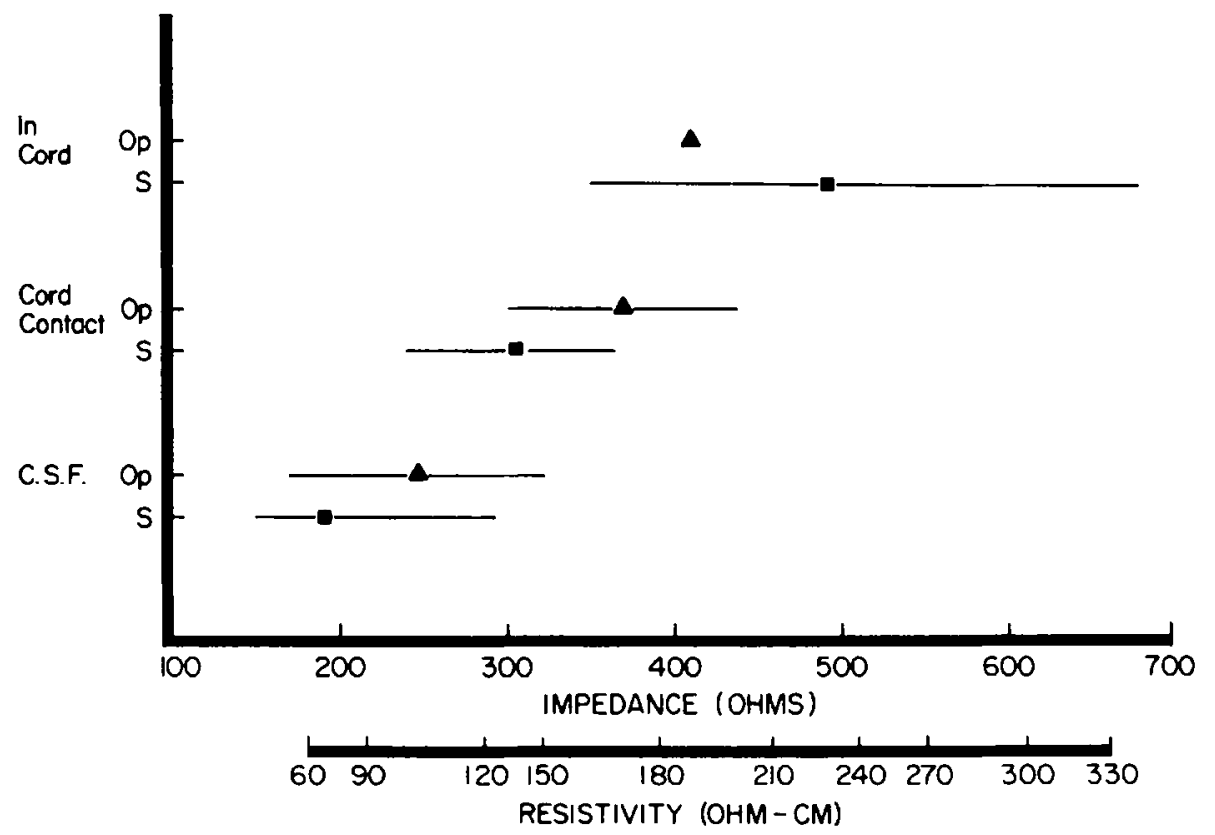

FIGURE 3. Resistivity values derived from increases in impedance. These are human values. Op refers to open cordotomy, and $\mathrm{S}$ refers to stereotaxic cordotomy. 


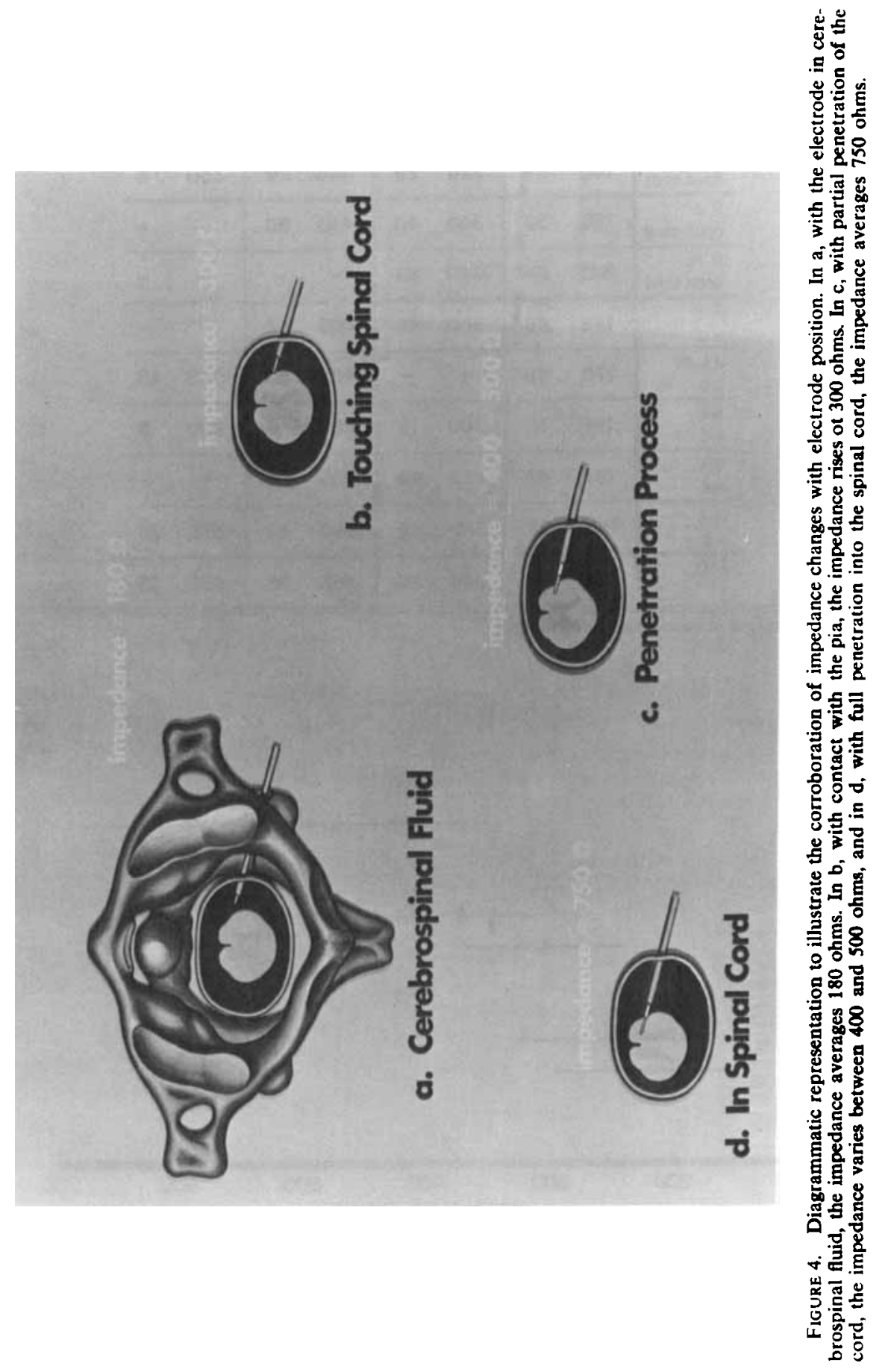


of $310 \mathrm{ohms}$, to a stable reading of $600 \mathrm{ohms}$, with a range of $350-750 \mathrm{ohms}$ (FIGURE 3). The figure is a composite of measurements during cordotomies. When the stable mean reading of 600 ohms is reached, radiofluoroscopy usually shows the electrode tip to be at or across the midline of the spinal canal by $0-5 \mathrm{~mm}$ (FIGURE 4).

It is important to convert the measurement of impedance to the standard readings for resistivity $(\mathrm{ohm}-\mathrm{cm})$. It can be stated from our previous laboratory experiments ${ }^{12}$ that the average impedance in the anterolateral part of the spinal cord, which is mainly myelinated fibers, when recorded in this fashion with use of the standard cordotomy 3 millimeter-tip electrode, is in the order of $280 \mathrm{ohm}$ $\mathrm{cm}$. or 600 ohms (FIGURE 5).

Our results are in agreement with those of Ranck and BeMent, ${ }^{7}$ who measured the specific impedance in the transverse direction of the dorsal columns of the spinal cord in cat and then again measured it in the longitudinal direction. The results show that the impedance of the transverse direction of the dorsal column is in the order of $600-1,200 \mathrm{ohm}-\mathrm{cm}$. The specific impedance in the longitudinal direction is in the order of $138-212 \mathrm{ohm}-\mathrm{cm}$. Our measurement of impedance of the anterolateral column is the result of measuring transverse and longitudinal impedance. The results, when the electrode tip is presumably in the cord, have a range from about $160-340 \mathrm{ohm}-\mathrm{cm}$. This large variation is probably not due to the variation in electrode-tip size, since the standard electrodes were used. It could be due to the fact that the electrode tip may be deep enough to touch the gray matter, or, more probably, that the proximal part of the exposed tip may not be fully in the anterolateral quadrant of the spinal cord, and as a result would be in contact partially with cerebrospinal fluid; the resultant reading of the impedance therefore would be lower. Taking the result as a whole, however, it

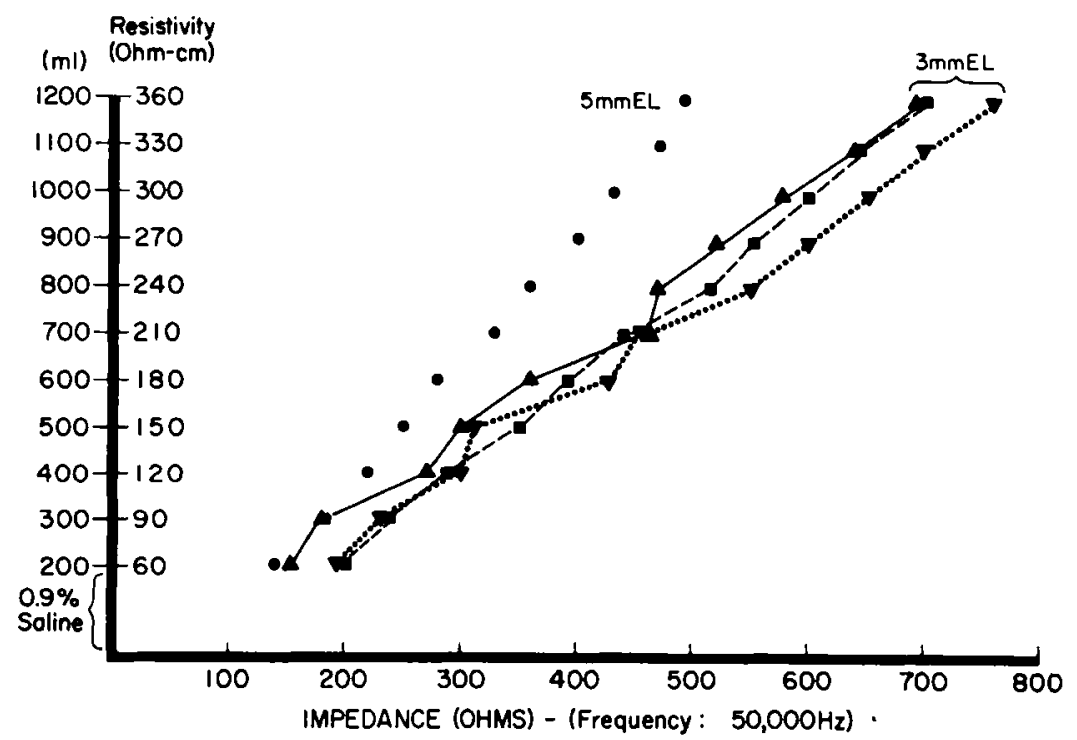

Figure 5. This graph demonstrates the conversion of impedance (ohms) recorded by three similar electrodes ( $3-\mathrm{mm}$-long tips) and another similar electrode (which has a 5-mm-long tip) into resistivity $(\mathrm{ohm}-\mathrm{cm})$. This was achieved by starting with $2: 0 \mathrm{ml}$ of $0.9 \%$ sodium chloride solution and diluting up to $1,200 \mathrm{ml}$. 
still lies within the two ranges of readings taken by Ranck and BeMent ${ }^{7}$ for the dorsal columns of cat. Freygang and Landau ${ }^{8}$ reported the specific impedance of cat subcortical white matter to be about one and a half times that of the cortex, or $333 \mathrm{ohm}-\mathrm{cm}$. It is therefore important to provide a conversion graph, so that the electrodes one uses for impedance measurements can be calibrated into resistivity and the results used to compare with those from other investigators using other types of electrodes in other situations.

\section{Electrical. Stimulation}

Presuming, from the impedance measurements, that the electrode is in the spinal cord, monofocal stimulation is then carried out further to localize the tip of the electrode. ${ }^{9-11}$ With use of low- and high-frequency stimulation, it is possible to judge the position of the electrode tip in the anterolateral quadrant of the cord from the resultant motor and sensory responses and the voltages required to produce them. ${ }^{12}$

\section{THE LESION}

As in any stereotaxic procedure, it is mandatory to know and be able to control the volume and the shape of the lesion as well as the site at which it is made. Presently, we are able to produce small, precise lesions with use of a radiofrequency generator operating at 70-80 milliamperes of current in increments of 15 seconds. It has been our practice to increase the lesion's size and position by varying the position of the electrode within the anterolateral quadrant of the cord as necessary. Clinical testing of the analgesic levels as the lesion is enlarged affords further corroboration of the electrode position. The maximum lesion size occurs at 15-20 seconds ( $2 \times 4 \mathrm{~mm}$ lesions $)$ and is indicated by a decrease in the radio-frequency current.

\section{CORrelation of ANalgesia with the Lesion}

Correlation of the areas of analgesia obtained as the lesion is made with the estimated position of the electrode corroborates the presence of two clinically useful patterns within the lateral spinothalamic tract (FIGURE 6). One is a dermatomal pattern, in which the cervical fibers are more anteromedial and the sacral fibers most posterolateral, close to the dentate ligament, with the thoracic and lumbar fibers interposed; and the other is a pattern for modality in which the superficial pain, temperature, deep pain, and visceral pain are disposed from without to within.

Thus, radiologic techniques guide the electrode to the anterolateral quadrant of the spinal cord, impedance measurements assure its penetration into the cord, and the techniques of stimulation permit estimation of its position within the anterolateral quadrant of the cord. Each of these methods is essential, since each gives a different degree of accuracy.

\section{Discussion}

Stereotaxic cordotomy in no way changes our already stated criteria in selection of candidates for open cordotomy, but it has greatly reduced our contraindications to the procedure. Previously, we were reluctant to perform the procedure on any patient with a short life expectancy, and it is to this type of patient that the benefits of cordotomy has accrued. Stereotaxic cordotomy is evolving as a better pro- 


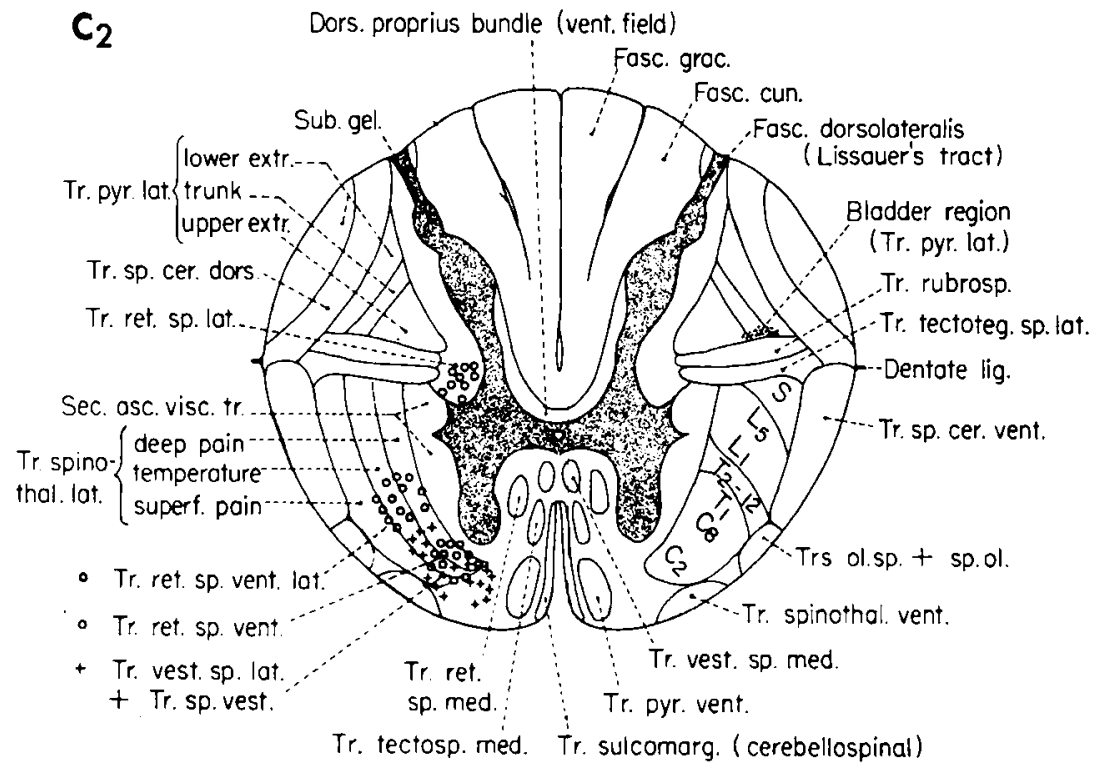

Figure 6. Diagram. Spinal cord at the level of $\mathrm{C} 2$ to illustrate the dermatomal and modality pattern across the lateral spinothalamic tract.

cedure than the open cordotomy, not because it is easier, but because just as satisfactory results can be achieved, complications lessened, and its benefits extended to sicker patients. However, since this is essentially a blind procedure, it is necessary to replace the visual localization of the lesion site by neuroradiologic and electrophysiologic techniques.

\section{REFERENCES}

1. SPILlER, W. G. 1905. The occasional clinical resemblance between caries of the vertebrae and lumbothoracic syringomyelia, and the location within the spinal cord of the fibres for the sensations of pain and temperature. Univ. Pa. Med. Bull. 18: 147.

2. Spiller, W. G., E. Martin. 1912. The treatment of persistent pain of organic origin in the lower part of the body by division of the anterolateral column of the spinal cord. JAMA 48: 1489.

3. Muli.an, S. 1966. Percutaneous cordotomy for pain. In Pain. R. S. Knighton and P. R. Dumkc, Eds. : 321-330. Little, Brown \& Co. Boston, Mass.

4. Mullan, S., P. V. Harper, J. Hekmatpanah, H. Torres \& G. Dobbin. 1963. Perculaneous interruption of spinal-pain tracts by means of a strontium ${ }^{90}$ needle. J. Neurosurg. 20: 931.

5. Rosomoff, H. L., F. Carroll, J. Brown \& P. Sheptak. 1965. Percutaneous radiofrequency cervical cordotomy: technique. J. Neurosurg. 23: 639.

6. Lin, P. M., P. L. Gildengerg \& P. P. Polakoff. 1966. An anterior approach to percutaneous lower cervical cordotomy. J. Neurosurg. 25: 553.

7. RanCK, J. B., JR. \& S. I. BEmFnt. 1965. The specific impedance of the dorsal columns of cat: an anisotropic medium. Expl. Neurol. $11: 451$.

8. Freygang, W. H., JR. \& W. M.LAndau. 1955. Some relations between resistivity and clectrical activity in the cercbral cortex of the cat. J. Cell. Comp. Physiol. 45: 377.

9. Mullan, S. 1966. Percutaneous cordotomy for pain. In Pain. R. S. Knighton and P. R. Dumke, Eds. : 321-330. Little, Brown \& Co. Boston, Mass. 
10. Sweet, W. H., J. C. White, B. Silvferstone \& R. Nilges. 1950. Sensory responses from anterior roots and from surface and interior of spinal cord in man. Trans. Am. Neurol. Ass. 75: 165.

11. Taren, J. A., E. A. Kahn \& T. Humphrey. 1969. The surgery of pain. In Correlative Neurosurgery : 464-508. Charles C Thomas. Springfield, Ill.

12. TAReN, J. A., R. Davis \& E. C. CrosbY. 1969. Target physiologic corroboration in stereotaxic cervical cordotomy. J. Neurosurg. 30: 569. 